\title{
Experiments in Active Learning through Project Across Courses
}

\author{
Mehul S Raval*, Ratnik Gandhi" \\ *School of Technology, Pandit Deendayal Petroleum University, Gandhinagar, India \\ *mehul.raval@sot.pdpu.ac.in \\ "ratnik.gandhi@gmail.com
}

\begin{abstract}
Active learning is an effective technique for imparting domain knowledge and life skills. However, it is an extremely resource hungry model. The proposed work shows the implementation of active learning for an engineering program in a constrained environment. It uses a project spanning across multiple courses, taught by different faculty, as a technique for active learning. With an aim to experiment with this technique, students were given challenging real-world problems. The proposal describes the goals of these pedagogic experiments, design constraints, projects content, deliverables, implementation methodology, and quantitative analytics. The effectiveness of ongoing experiments has been assessed over three years with more than 200 student participants. Statistical analysis and student's satisfaction survey reveals that a project across courses increases the intrinsic motivation of a student while imparting domain knowledge and life skills.
\end{abstract}

Key words

Active Learning, Engineering-education, Project Across Courses, Project based learning, Project in a Course

\section{INTRODUCTION}

Deductive reasoning has been a traditional way of teaching in engineering education (Berrett, 2012; Dewey, 1980). Engineers of 21st century [10], must possess deep domain knowledge to solve complex problems and should also be sensitive to people, society and the environment [28], [46]. They must work at the intersection of feasibility, desirability, and viability of the problem [22]. The engineer must be $T$-shaped thinkers [37]. However, innovations in pedagogical techniques to incorporate these changes are slow or essentially absent in India. Some challenges for the India are: Lectures still dominate the Engineering teaching; Almost muted class interactions; Dilution of student motivation; Randomly adding a project to every course, increases the academic load.

One possible "Do - Learn" way of solving the challenges and to potentially produce a new-age Engineer is through Active Learning (AL) [15] [23] [42]. AL keeps "problem/project", "challenge" and "goals" at the centrum. Then, the learner discovers content, concepts, and mechanisms while addressing the problems [29] [42]. The project-based learning (PBL) [20] [22] is very important active learning strategy for developing competencies of a modern engineer [14] [32] [39]. Engineers must understand the culture, needs, social norms, habits, and other human factors and use them in engineering design. It is a thoughtful, systematic and intelligent process but it also produces conflict between divergent inquiry and deterministic engineering approach [16] [30].

The most common implementation of active learning is through student projects [22]. Projects increase students' engagement significantly compared to traditional classroom mode [23]. The meta-analysis of examination scores for undergraduate education indicates that AL improves 
the student classroom experience as compared to traditional lecturing [18]. It also supports promotion of undergraduate research [27] activities. AL had been tested for various domains of engineering. In Computer Science and Engineering it's used for learning software engineering [50], basic programming [28], introducing computing [6] [45] and industrial informatics [8]. One can find similar attempts in subjects of Electronics Engineering [19], Electrical Engineering [26] [49], Power Electronics, Robotic Arm [31] [34] [35], Computer Vision [7] [21], and Machine learning [40]. For Mechanisms and Machine Theory subject in Mechanical Engineering [13] presented use of Android App for auto evaluating concepts and improvement in learning.

One of its recent renditions of AL is known as Hybrid PBL (H-PBL) [48]. This mode presents a course through traditional lecturing and uses project in a course (PIC) for PBL. The digital image processing course uses H-PBL implementation [48] yielding mixed results on learning. Another attempt [9] analyzed integration, and timing of conventional and AL course components. The analysis showed improvement in learning outcomes and H-PBL have a longterm impact on competence.

Students undergoing AL courses display improvement in; 1. domain knowledge; 2. team coordination; 3. hands on skill; 4. productivity; 5. self-esteem; 6. appreciation towards multidisciplinary work. However, a mere imitation of AL techniques will not produce satisfied and better learning students [43]. General challenges for AL implementation are discussed in following subsection.

\section{A. General Challenges for AL implementation}

1. Design of a complex problem is a non-trivial task.

2. A demand for dedicated spaces on the campus is high.

3. Ideally AL needs inexhaustible supply of resources.

4. It's difficult to scale AL pedagogy for large classes.

5. The assessment of AL driven courses are very difficult.

6. Ideally AL needs customization of guidance for each student or a project team. It needs calibrated scaffolding.

7. AL requires a new approach for assessment as new skills are built [16]. For example, grading a team over project compared to evaluating an individual student.

8. AL demands substantial time and efforts over a long period of time from all the stakeholders.

A set of challenges, including some as listed above, adversely impact the Indian engineering education while implementing AL. Table I indicates number of students enrolled [2] in colleges monitored by the regulator All India Council for Technical Education (AICTE). It has proposed model curriculum for undergraduate engineering [3] and reduced norms about faculty to student ratio from 1:15 to $1: 20$ [33].

TABLE I: Engineering intake pan India [2].

\begin{tabular}{|l|l|l|}
\hline Year & Undergraduate (UG) & Postgraduate (PG) \\
\hline $2017-18$ & 1476608 & 185910 \\
\hline
\end{tabular}

The structure for typical UG engineering program is shown in Table II. This means on an average student has to cover 6 subjects per semester considering 3 credits per course. This 
leaves little room for new pedagogic experimentation. As argued in [43] AL needs time to fructify but heavily credit loaded curriculum may not allow this to happen. On the other hand, the intake for engineering students has also grown exponentially (Table III). This strains skilled faculty requirements.

TABLE II: Standard Engineering Curriculum [3].

\begin{tabular}{|l|l|}
\hline Category & Credit \\
\hline Humanities and Social Science & 12 \\
\hline Basic Science Courses & 25 \\
\hline Engineering Science & 24 \\
\hline Professional core courses & 48 \\
\hline Open subjects- Electives & 18 \\
\hline Project work, seminar and internship & 15 \\
\hline $\begin{array}{l}\text { Mandatory Courses - Environmental Sciences, Induction training, } \\
\text { Indian Constitution, Essence of Indian Traditional Knowledge }\end{array}$ & $\begin{array}{l}\text { Non } \\
\text { Credit }\end{array}$ \\
\hline Total & 160 \\
\hline
\end{tabular}

TABLE III: Growth in intake [2].

\begin{tabular}{|c|c|c|c|c|}
\hline Year & UG Institutes & $\begin{array}{c}\text { UG } \\
\text { students }\end{array}$ & $\begin{array}{c}\text { PG } \\
\text { Institutes }\end{array}$ & PG students \\
\hline $2004-05$ & 1346 & 439689 & 979 & 23100 \\
\hline $2014-15$ & 3389 & 1693771 & 2300 & 212070 \\
\hline \% Growth & 151.7 & 285.2 & 134.9 & 818 \\
\hline
\end{tabular}

Mapping of complex Blooms' taxonomy [5] on active learning is required when developing pedagogy for the future of engineering education. It is also important to assess entire AL exercise including student evaluations. There are some existing frameworks [11] [17] [50] to evaluate end-to-end AL experiments but they are constrained to specific domains. Extra work is required to show their effectiveness outside the domain of their implementation [25]. Methods presented in [11] [17] are oriented towards focused knowledge acquisition and they do not provide general AL guidelines.

\section{B. Project Across Courses}

Against the challenges, the purpose of the work is to propose Project Across Courses (PAC) as AL pedagogy in a constrained environment. PAC is broadly defined as a pedagogy in which a project spans courses - offered to a same group of students - and is focused on concepts learned in an individual subject. It helps the student to weave together concepts spanning across courses which in turn improve their domain knowledge and hands-on skills (technical skills). It also develops abilities like teamwork, project and time management, communication, and dealing with difficult situations (life skills.) In order to make student deal with real world inconsistencies, some part of the project definition is deliberately kept open-ended. This also forces students to think about alternative solutions to the problem.

Putting PAC in the perspective of state-of-the-art AL, we observe the following:

- Most approaches lack generic framework in explaining pedagogy for the PAC.

- They are restricted to specific domain. 
- To the best of our knowledge, there is no case study to discuss AL approach in a resource constrained environment, over a large scale and long-time frame.

The paper shows PAC as an effective tool to help students build technical and life skills. Design of PAC is based on iterative approach supervised over the period of three years involving 200+ students, 2 faculty, and 6 teaching assistants (TA) at University in India. The rest of the paper is organized as follows, Section II discusses the context of our implementation at the University, and its related academic constraints. Section III address the pedagogical approach, learning objectives and methodology. Section IV presents the projects. Section V results, and educational assessment. Finally, the conclusion in Section VI.

\section{ACADEMIC CONSTRAINTS FOR COPY BOOK AL}

\section{A. Background}

The school offered 4-year bachelor programs in Information and Communication Technology (ICT), Chemical (ChE) and Mechanical (ME) Engineering, a 2-year Master program in Data Science and Analytics and Doctoral programs. A significant chunk of courses at school have a strong inbuilt project component contributing up-to 30\% in an evaluation. However, AL attempts were restricted to a Project In a Course (PIC - Fig. 1). The genesis of the pedagogic experimentation can be traced back to Monsoon semester of 2015 when a PAC for Linear Algebra (LA) and Signals and Systems (SS) commenced.

\section{B. Academic Constraints and Demographics}

The set of typical constraints for most Indian institutes are as follows:

1. The UG students are admitted through a centralized admission process administered by the Gujarat State Government [1]. It implements 50\% reservation policy for students (reserved category) with under-privileged background and rest 50\% is known as unreserved or open category.

2. At present, the students to faculty ratio is high (20:1).

3. There is a demographic variation in the students coming to the school. For example, some freshman clears grade XII (qualifying) exam in English, while many others clear it in the Gujarati; the native language. At the school, British English is used as a medium of instruction and the native language student experiences learning differently.

4. There is a significant variation in the merit rank of the students admitted through the Admission Committee for Professional Courses (ACPC) [1].

5. The faculty has background in the deductive form of learning.

6. There is no full-time dedicated space for students of an AL course. Though they have multiple spaces available for part-time.

7. The school is not residential. All the students stay off campus.

III. PROJECT ACROSS COURSES, LEARNING OBJECTIVES AND METHODOLOGY 
Considering constraints and perspective, it is clear that the transition from "Learn-Do" to "DoLearn" should be done carefully over a period of time. The authors reviewed following alternatives for AL:

1. Multiple projects across several courses and semesters [44].

2. Co-teaching of a course by a group of faculties [21] [40].

3. Courses with $30 \%$ or greater weight for project and rest covered through requisite theory [8-9].

4. A full course with a project at the center [19] [49].

Then, the authors decided to initiate offering PAC in a semester. The idea of PAC is exemplified in Fig. 1.

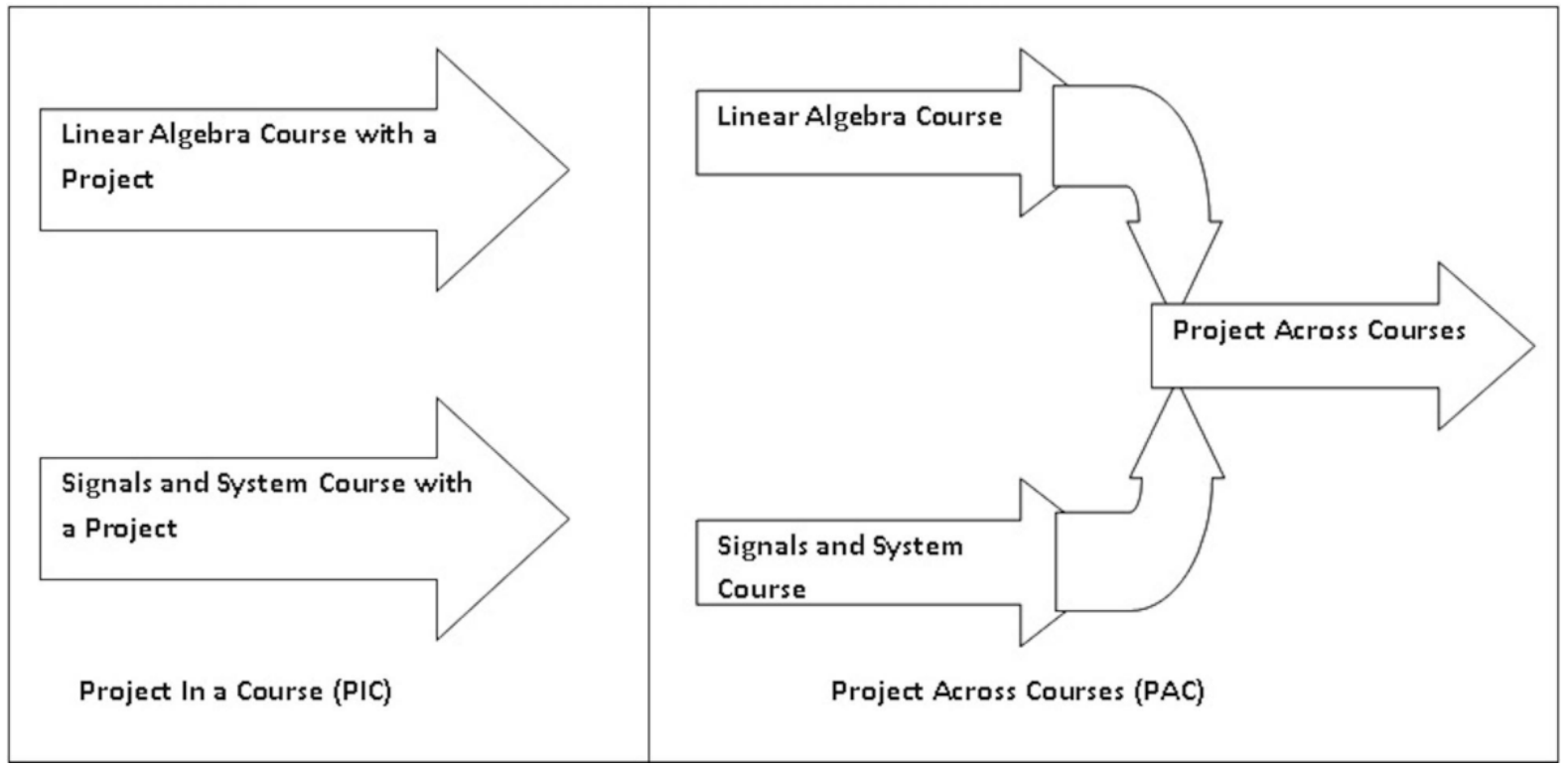

Fig. 1: Project in a Course vs. Project Across Courses.

It shows PAC for LA and SS to the students of semester III. The PAC incorporates following essential features of AL [49].

- Interdependence: teamwork towards a clearly defined goal.

- Individual accountability.

- Face to face interactions.

- Development of interpersonal skills and teamwork.

- Reflection: Periodically the team must check progress with "plus" and "delta" [22] analysis.

Moreover, PAC has its own set of unique features listed as follows:

1. Provides a platform for qualitative and quantitative academic oriented interactions between faculty. This is one step closer to co-teaching in India.

2. Provides real-world context and multiple facets to see the same project through lens of multiple courses. This inherently calls for multidisciplinary inputs which are derived with a complementary set of courses. For example, solving image compression problem using transforms (uncovered in Signals and Systems) computed using matrices 
(uncovered in Linear Algebra). This increases content learning in the respective courses, improves intrinsic motivation as students perceive their need to know [43].

3. Reduces students' academic burden of executing multiple projects.

4. Student overcomes their demographic inhibitions through team dynamics.

\section{A. Proposed Learning Objectives}

The expected outcome of the PAC covers technical and life skills. At end of the project, the student should be able to meet the following objectives in Table IV.

TABLE IV: Proposed learning objectives for PAC.

\begin{tabular}{|c|l|l|}
\hline Objectives & \multicolumn{1}{|c|}{ Description } \\
\hline O.1 & Apply technical skills from multiple domains to a project. \\
\hline O.2 & Design, develop, and programme algorithms. & \\
\hline O.3 & $\begin{array}{l}\text { Project management, time management, verbal and written } \\
\text { communication skills. }\end{array}$ \\
\hline O.4 & Deal with abstract problem statement or data. & \\
\hline O.5 & Able to relate ideas across domains. \\
\hline
\end{tabular}

\section{B. Methodology}

The careless design and implementation of AL can lead to student frustration [38] [41]. Therefore, the PAC follows careful iterative design cycles, i.e., conception, design, implementation, assessment, and conclusion [22] During conception and design phase, faculty and TAs weigh different project definitions. Discussions also involve students from the class to achieve convergence for the definition. Next, TAs carry out quick implementation with inputs from faculty. This helps to gauge the target group response to a project definition.

Faculty form project teams randomly based on recommendations given in [38] [41]. This breaks student's tendency to cluster, and the team is balanced in terms of skills and gender. The project definition is rolled out to the teams with clear instructions and they are given enough scaffolding for steady progress. The implementation phase is supported by selfreflections, group reflections, interactions with faculty and TAs, monitoring by faculty, and formal feedback.

The project groups are ranked based on levels [5]: remember, understand, apply, analyze, evaluate and create. They are based on categories; excellent, very good, good, fair and needs improvement. The team is evaluated based on inside-class and outside-class participation, behavioral observations, a viva voce exam, peer feedback, informal discussions, presentation in class, computer programs, report submission, and regularity. The individual performance is tracked through peer review and informal interactions with an individual team member. During the project run and after its completion, faculty, TAs and students carry out reflections to improve learning for the student team.

The technology was used throughout the project development. The use of technology helped in effective communication, collaborative development, posting and responding on forums, managing the resources, peer review, and collection of formal feedback. The design phase discussions use Google docs and sheets for the exchange of the ideas. The sharing allowed simultaneous editing and commenting on the document. The randomization in the team 
formation is done using the spreadsheet program. The learning management system (LMS) is used to roll out the project definitions to the students. The discussions forums on the LMS has been used by groups for posting and resolving the query. The LMS feedback systems and Google Forms are used to collect the formal feedback system. During one of the PAC run a web-based design tool (CATME tool) was used to collect the peer review. Later due to commercialization, it was not used and instead Google forms were used. The project teams also resorted to Git repository which provides a web-based interface for collaborative development. They used Google Drive and DropBox for sharing and co-developing the documentation.

\section{PROJECT DESCRIPTION}

\section{A. PAC for Linear Algebra and Signals and Systems, Semester III}

The first PAC conducted during Monsoon 2015, by the authors, was between two courses Linear Algebra and Signals and Systems (LA - SS). These courses are offered to Bachelor of Technology (BTech) ICT, Semester III students. Both courses have 4 credits with 3 Lecture and 1 tutorial per week and they run for 16 weeks in a semester. The course contents are as follows:

\section{1) Course Contents:}

Linear Algebra: Linear equations, Matrix Algebra, Determinants, Vector Spaces, Eigenvalues and Eigenvectors, Orthogonality and Least square, Symmetric Matrices and Quadratic Forms.

Signals and Systems: Idea of abstraction, Continuous and discrete-time signals, System properties: Linearity, Shift invariance, Convolution, Frequency domain representations: Fourier Series, Fourier Transform, System representations

The course contents of LA-SS are a natural ally to arrive at project definition spanning them. The signals and systems make use of linear algebra on theoretical and algorithmic fronts. This conjunction allows a better understanding of algorithmic impact. This led authors to the domain of image compression for the definition of a PAC which is discussed in next subsection.

\section{2) Motivation:}

The project was about segmentation of an image compressed with lossy algorithm. The image segmentation partitions an image for analysis. The project needs many low-level image processing techniques like computing Principal Component Analysis (PCA), binarization, labeling, and segmentation. The team had to understand and implement linear algebraic techniques and frequency transform to complete the project.

\section{3) Project definition:}

Capture a panoramic image of the students seating during a class in progress, compress it and count number of student's heads in the image.

Final deliverable:

A program which gives an exact headcount in an image with the highest compression.

\section{4) Time line:}


This was a project with the timeline of 9 weeks with bi-weekly submissions. The suggested week wise plan and deliverables are as follows:

TABLE V: Time line for LA-SS project.

\begin{tabular}{|l|l|}
\hline Week & \multicolumn{1}{c|}{ Task } \\
\hline 1 & Modelling image as an algebraic object \\
\hline 2 & Image pre-processing \\
\hline 3 & Image compression, Frequency transformation \\
\hline Deliverable & 1-page report (LATEX- single column format). \\
\hline 4 & Implement the segmentation \\
\hline 5 & Quick implementation \\
\hline 6 & Studying the real-world difficulties pose, illumination, occlusion. \\
\hline Deliverable & 2-page report (LATEX- single column format). \\
\hline 7 & Solution implementation \\
\hline 8 & Improvisation on the solutions \\
\hline 9 & Final Presentation and Report submission \\
\hline
\end{tabular}

A sample input and output image of a team project is shown in Fig. 2.

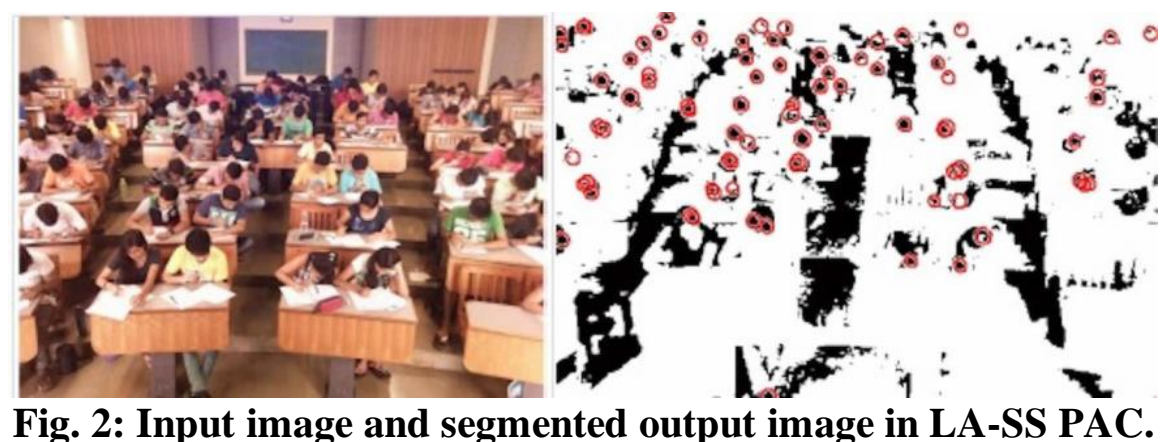

\section{5) Team formation, Monitoring and Assessment:}

The team was formed by faculty with pseudo-random selection [38][41]. This breaks the student tendency to cluster in a cohesive group. They will be out of their comfort zone and work with a new person. The faculty attempted uniform distribution in terms of technical, life skills, and gender.

The project started with 1.5-hour introductory session by faculty on the project scope and team principles like sharing of responsibilities according to member strength, systematic and consistent team meetings, continuous progression for the intermediate and final goals, independent and interdependence in teamwork, transparent communication, reporting and project management. Since the students required conceptual background for starting the project, it did not start until week five into the semester. Research papers were suggested to the LA-SS students for reading. This step inculcated a habit to review state-of-the-art material in semester III students.

The project started with a simple set of statements and allowed students to take incremental steps, i.e., students have the freedom to implement existing algorithm and improvise them. Loose problem statement allowed students to apply different techniques during each low-level stage, resulting in variants of the solution. Modular project guidelines provided scaffolding to the team with encouragement for experimentation. 
The team progress was monitored through written report submission after weeks 3,5 and 7 . Each team also made a presentation in front of their class during week 5 and after the conclusion of the project. After week 5 each team was given 10 mins. for presentation, while teams are given 15 mins for final presentation. Each team member was expected to present the progress in English. It was communicated that team must spent 3 Hours/Week on the PAC. Informal TA-student, faculty-student, and faculty-TA discussions helped to gauge the team progression. The project deliverables include written reports, copies of presentations, and program code. Student team used either MATLAB, C++ or Python-Open CV for coding.

The project had a weight of $20 \%$ in over-all evaluation for both the courses. The other course assessment components being mid-semester exam (20\%), end semester exam (40\%), assignments (20\%). The assessment of project was based on following criteria:

- Midterm evaluation (30\%) based on presentation, 1-page report, coding, participation

- End term evaluation (70\%) based on presentation, 10-page report, final program, participation, inputs from TAs.

The individual participation is tracked through peer review and informal interactions with the team members.

\section{B. PAC for Algorithm and Optimization for Big Data (AOBD) and Machine Learning (ML)}

In another PAC implementation, the authors paired courses on Algorithm and Optimization for Big Data and Machine Learning (AOBD - ML) during Winter semesters of 2014-2015, 201516, and 2016-17 at the school. These are core courses for Master of Technology (MTech) in Data Science and Analytics program and offered to students in their second semester. These courses were also offered as an elective to BTech Semester VI ICT. Both courses have 3 credits of 3 Lectures per week and courses run for 16 weeks/semester. The course contents are as follows:

1) Course Contents:

$A O B D$ : Linear algebraic analysis, regression, Markovian analysis, Linear - nonlinear optimization problems, numerical and continuous analysis.

$M L$ : Supervised learning, Bayesian decision theory, Dimensionality reduction, Unsupervised learning through clustering, Artificial Neural Network and Kernel Machine.

\section{2) Motivation:}

Optimization and analytical aspects of low-level ML algorithms are covered in AOBD while tools and its related theoretical background is supported by ML. Encouraged by the feedback, the problem definitions for the AOBD - ML PAC was gradually changed for each run.

\section{3) Project Definition: (Winter 2014 - 15):}

Given a 30 frames per second full high definition video, detect faces in the frames.

Project Definition: (Winter 2015 - 16):

Capture a High Definition (HD) video. Create a database of videos and mugshots. Identify the face from the video frames and mugshots. Use face detection developed in the previous year.

Project Definition: (Winter 2016 - 17): 
Implement Probabilistic PCA (PPCA) and develop Generative Model (GM) for real images.

4) Time Lines:

These projects spanned 9 weeks in a semester. The suggested timelines were as follows:

Winter $2015-16$

TABLE VI: Time line for the 2015 - 16 project.

\begin{tabular}{|l|l|}
\hline Week & \multicolumn{1}{c|}{ Task } \\
\hline 1 & Creating database \\
\hline 2 & Survey Face Recognition \\
\hline 3 & Implementation and comparison of distance metrics. \\
\hline Deliverable & 1-page report (LATEX- single column format). \\
\hline 4 & Implement the segmentation \\
\hline 5 & Quick implementation \\
\hline 6 & Comparisons of results \\
\hline Deliverable & 2-page report (LATEX- single column format). \\
\hline 7 & Generalize algorithms for real video \\
\hline 8 & Propose techniques to improve the solution \\
\hline 9 & Presentation and Report submission \\
\hline
\end{tabular}

Winter 2016 - 17

TABLE VII: Time line for the 2016 - 17 project.

\begin{tabular}{|l|l|}
\hline Week & Task \\
\hline 1 & Implementation of PPCA, review, task division. \\
\hline 2 & Understand and implement Expectation Maximization (EM) algorithm \\
\hline 3 & Compare PPCA and EM \\
\hline Deliverable & 2-page report (LATEX- single column format). \\
\hline 4 & Study and implementation of a Deep Neural Network (DNN) \\
\hline 5 & Generative Models using PPCA \\
\hline 6 & Model Improvisation \\
\hline Deliverable & 2-page report (LATEX- single column format). \\
\hline 7 & Generalize algorithms for real images \\
\hline 8 & Propose techniques to improve the solution \\
\hline 9 & Presentation and Report submission \\
\hline
\end{tabular}

The samples of project outcomes for AOBD - ML during Winter 2014-15, Winter 2015 - 16 and Winter 2016- 17 are shown in Fig. 3, Fig. 4, and Fig. 5 respectively. 

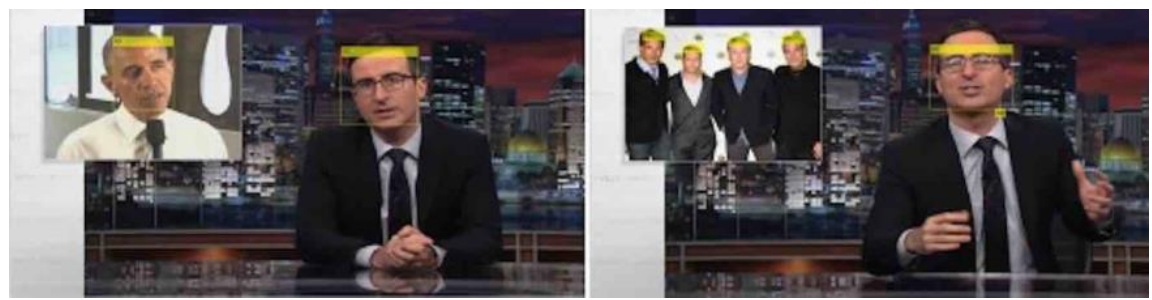

Fig. 3: Localizing Faces in a streaming High Definition video. ML - AOBD PAC Winter 2015.

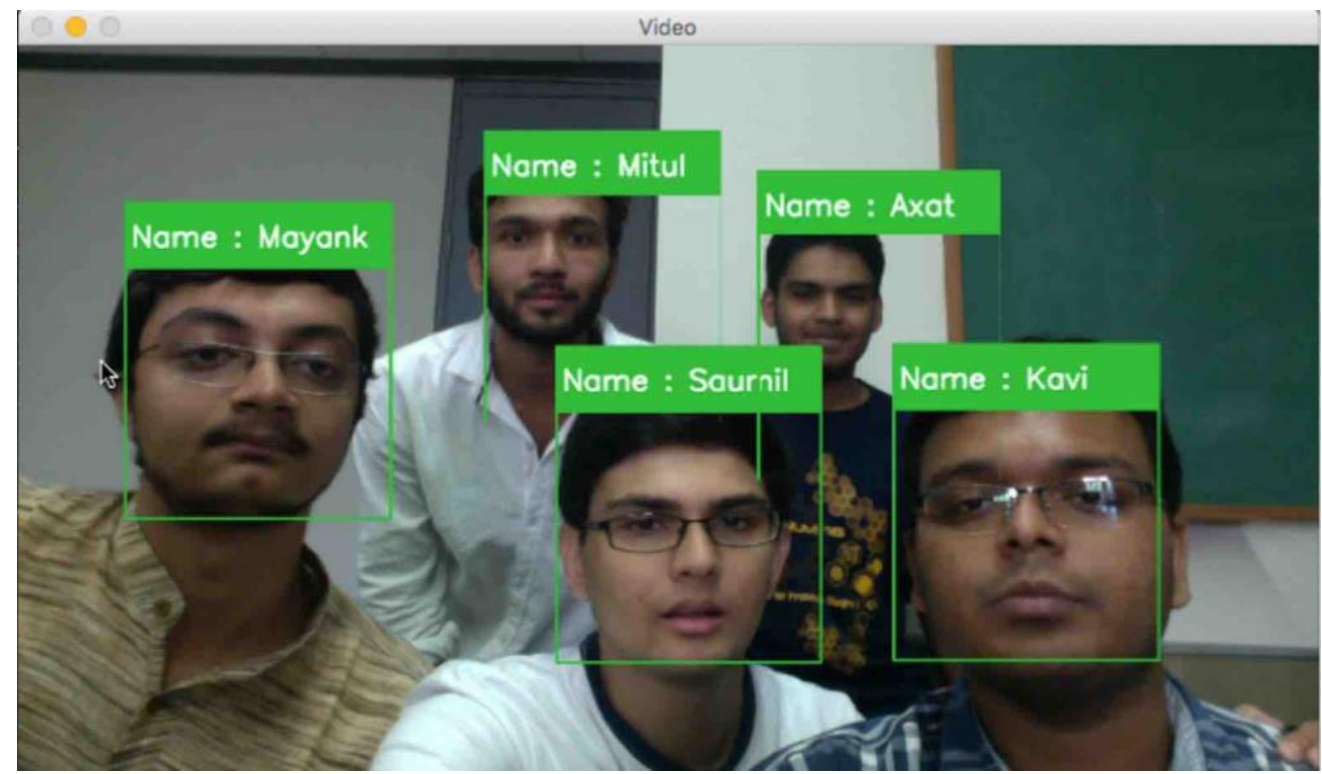

Fig. 4: Person Recognition. ML - AOBD PAC Winter 2015-16.
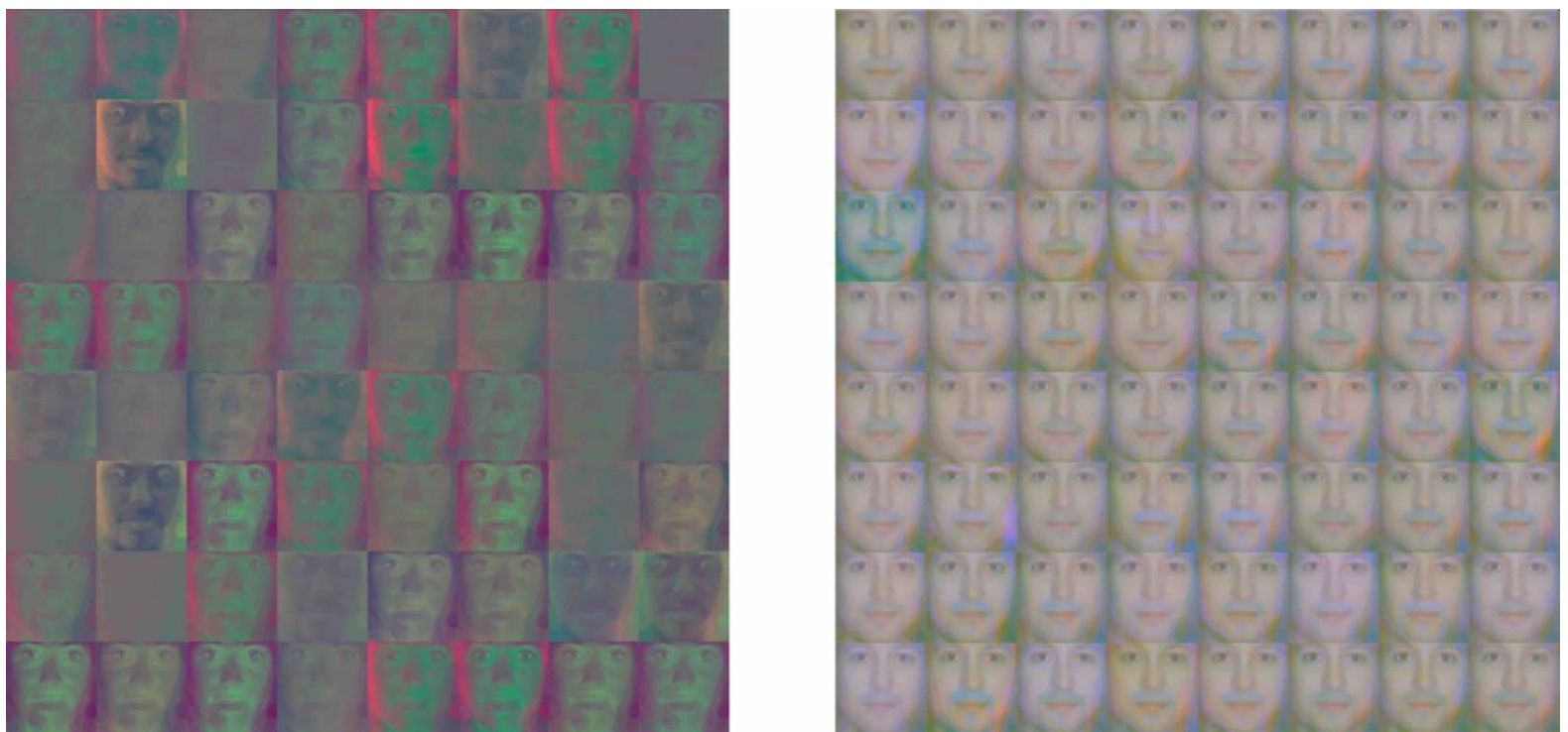

Fig. 5: Generating Faces using GAN after 200 and 2500 epochs. ML - AOBD PAC Winter 2016-17.

5) Team formation, Monitoring and Assessment:

The students AOBD-ML are heterogeneous as compared to LA - SS. There is a mix of BTech, $\mathrm{MTech}$, and $\mathrm{PhD}$ students. Student team comprising of undergraduate and postgraduate 
students were pseudo-randomly formed by the faculty [38] [41] for the uniform distribution. This added complexity in group dynamics.

The project started with a session by the faculty - introducing the project, discussing learning goals, objectives, expected outcomes, and team dynamics. The projects were initiated at four weeks into the semester. This allowed enough project background in class. The state-of-the-art material is suggested to students and it was expected that student digs deeper. The definition statements only specify the end objectives and the team choose different techniques to find a solution.

In this PAC, exploration of ideas by the team is given higher weight during evaluation than detection accuracy. Also, faculty provided guided suggestions and hints towards the goals. Just enough theory was delivered - providing a momentum through the class learning. Every week faculty set aside time to meet the teams. The teams presented the outcomes of the previous week which were collectively analyzed. Teams also discussed the problems and faculty shared common learnings with the team. The teams submitted reports in prescribed manner during the project. These reports were submitted through email to TAs, where they do a preliminary evaluation and share the results with the Faculty. At halfway through the project teams were asked to make a 10 minutes presentation and 5 minutes were set aside for discussions. Mandatorily all the team members had their part in the presentation. Towards the end of the project, teams made a presentation which discussed refined implementation.

The project had a weightage of $20 \%$ to $30 \%$ in over-all evaluation for both the courses. The other course assessment components are mid-semester exam (20\%), end semester exam (40\%), assignments $(20 \%)$. The rubric used for grading written reports has following components: formatting, literature review, analysis of the problem, design of the various problem subparts, conclusions. The projects were evaluated on similar lines as described in the section of LA-SS PAC.

\section{RESULTS, EDUCATIONAL ASSESSMENT AND DISCUSSIONS}

It is difficult to evaluate soft skills of a person [46] but it can be made reliable with multisource feedback [36]. We rely on student satisfaction survey for assessment of life skills and multi-source feedback through peer reviews, inputs from TAs, TA-student, student-faculty, faculty-faculty interactions, and faculty's own judgment about the project progression. The number of students participated in these PAC exercises are shown in Table VIII. The Table VIII shows students common to both courses i.e., LA - SS and AOBD - ML. The registration "numbers" for MTechs' in AOBD and ML are same, but the individuals were different for BTechs' in these courses cf. Table XI.

TABLE VIII: Students participation in PACs.

\begin{tabular}{|l|l|l|l|l|l|}
\hline Semester \& Courses & BTech & MTech & Total & Team Size & $\begin{array}{l}\text { Gender Ratio } \\
\text { (Female: Male) }\end{array}$ \\
\hline Monsoon 2014-15 LA - SS & 105 & - & 105 & $5 / 6$ & $25 \%: 75 \%$ \\
\hline Winter 2014-15 AOBD - ML & 16 & 16 & 32 & $4 / 5$ & $54 \%: 46 \%$ \\
\hline Winter 2015-16 AOBD - ML & 25 & 9 & 34 & $4 / 5$ & $54 \%: 46 \%$ \\
\hline Winter 2016-17 AOBD - ML & 47 & 6 & 53 & $4 / 5$ & $38 \%: 62 \%$ \\
\hline Total & 193 & 31 & 224 & & \\
\hline
\end{tabular}




\section{A. The Participants}

The observed variations in LA-SS vs. AOBD-ML students are as follows:

- LA - SS was more homogeneous class in terms of age group, background, demographics, exposure to the school academic practices from the freshman year. AOBD - ML had MTech students who are older (22 years+) than BTech(20 years+) and they have received BTech degree from institutes other University.

- Due to better coverage of prerequisites, BTech students had better mathematical foundation than MTechs.

- Motivational levels in undergraduate students were higher than postgraduate students. (Based on the observation that AOBD - ML were elective courses for BTech students).

- On an average about two-thirds of all the BTech students have secured more than $80 \%$ marks in their qualifying exams i.e., Higher Secondary School Certificate (HSC). On another hand, the number of MTech students with $80 \%$ or more in HSC exam was one-seventh in proportion.

- As AOBD-ML team members had registered for different electives, and students had different working schedules, it was difficult for them to find common working time for this project beyond class hours.

The LA - SS had the team size of 5 or 6 students and AOBD - ML had 4 or 5 students per team. The gender ratio (female: male) in a team was fairly balanced in all of these PAC exercises. Amongst the population, most students (about 95\%) were from the urban area and very few (about 5\%) from rural areas. Most students were staying at their homes with few residing in hostels.

\section{B. Student Satisfaction Survey: Goal Sheet and Peer Review}

\section{1) Goal Sheet:}

One of the most important aims for this pedagogic exercise is to check students' affinity towards PAC and to track their learning experiences as the project progresses. Along with the informal feedback throughout the semesters, set of questions were designed to quantify these outcomes. During anonymous surveys, students were asked to give opinion score (OS) and reviews through a goal sheet. Our goal sheet is inspired from a goal sheet designed by Jonathan Stolk and Robert Martello, F.W. Olin College of Engineering, MA. The goal sheet measures cognitive domain objectives of Bloom's taxonomy and specifically it is measuring the following for PAC:

- Development of technical and life skills.

- Student's learning experiences.

- Satisfaction with the project.

The goal sheet was discussed with the students before formal feedback. Each student in the class was asked to rate their choice on the set of goals (either they want to achieve, or they think they will achieve at the end of the project). A discrete scale of 0 to 10 was designed, where a 0 indicated preference for a project in a course (PIC) and a 10 means preference for the project across courses (PAC). The number of students participated in survey were: LA - SS (100\%), AOBD - ML - Winter 2014 - 15 (81\%), Winter 2015 - 16 (61\%), and Winter 2016 $17(88 \%)$. The set of goals in our goal sheet for (LA-SS or AOBD-ML) with their brief description is as under. Each PAC learning objective from Table IV is mapped to relevant goals and mentioned next to each goal. 
- G1. Hands-on Skills: Involving active participation; applied, as opposed to theoretical $[\mathrm{O} .2, \mathrm{O} .3]$.

- G2. Content Learning: Learning of concepts and content of courses through PIC vs. PAC $[0.1,0.5]$

- G3. Critical Thinking: It is the mode of thinking about any subject, content, or problem in which the thinker improves the quality of thoughts by skillfully analyzing, assessing, and reconstructing it. Critical thinking is self-directed, self- disciplined, self-monitored, and self-corrective thinking. [O.1, O.4, O.5]

- G4. Real-World Context: Learning that is designed so that students can carry out activities and solve problems in a way that reflects the nature of such tasks in the real world. [O.1]

- G5. Disciplinary Integration: How PIC vs. PAC will help integrate concepts and ideas of courses and disciplines. [O.1, O.5]

- G6. Intrinsic Motivation: Actively participating in the project because one enjoys the activity vs. doing it for the sake of grades/outcomes. [O.2, O.3]

- G7. Competence in multiple areas: Increase in abilities/skills/capabilities/proficiencies in multiple areas. [O.3, O.5]

- G8. Fairness of the project evaluation. Goal G8 does not relate to cognitive learning objectives defined by Bloom's taxonomy. Its purpose is to identify students' perception and confidence in evaluation mechanisms defined for PAC.

2) Peer Review:

The team members were asked to review their peer team member on a scale of 0 to 10 on the following set of points; 1 . Attends meetings regularly and arrives on time; 2. Contributes meaningfully to discussions; 3 . Completes team assignments on time; 4. Prepares work in a quality manner; 5. Demonstrates a co-operative and supportive attitude; 6. Contributes significantly to the success of the project.

Also, team members were asked to write qualitative feedback about their team members. The set of qualitative feedback questions were; 1 . How effectively did your team worked? 2. Were the behaviors of any of your team members particularly valuable or detrimental to the team? Explain; 3. What did you learn about working with a team from this project that you will carry into your next teaming experience? The student's responses were collected non-anonymously and they were available for review to the faculty members only.

\section{Educational Assessment: LA - SS}

The students of LA-SS courses had no prior experience of PAC. But they had experienced PIC through series of courses in the freshman year. The LA-SS PAC was their first experience of a joint project. Goal-wise mean opinion score (MOS) for LA-SS PAC was collected twice in a semester - after mid-PAC evaluation and after end. The MOS are shown in Fig. 6. 


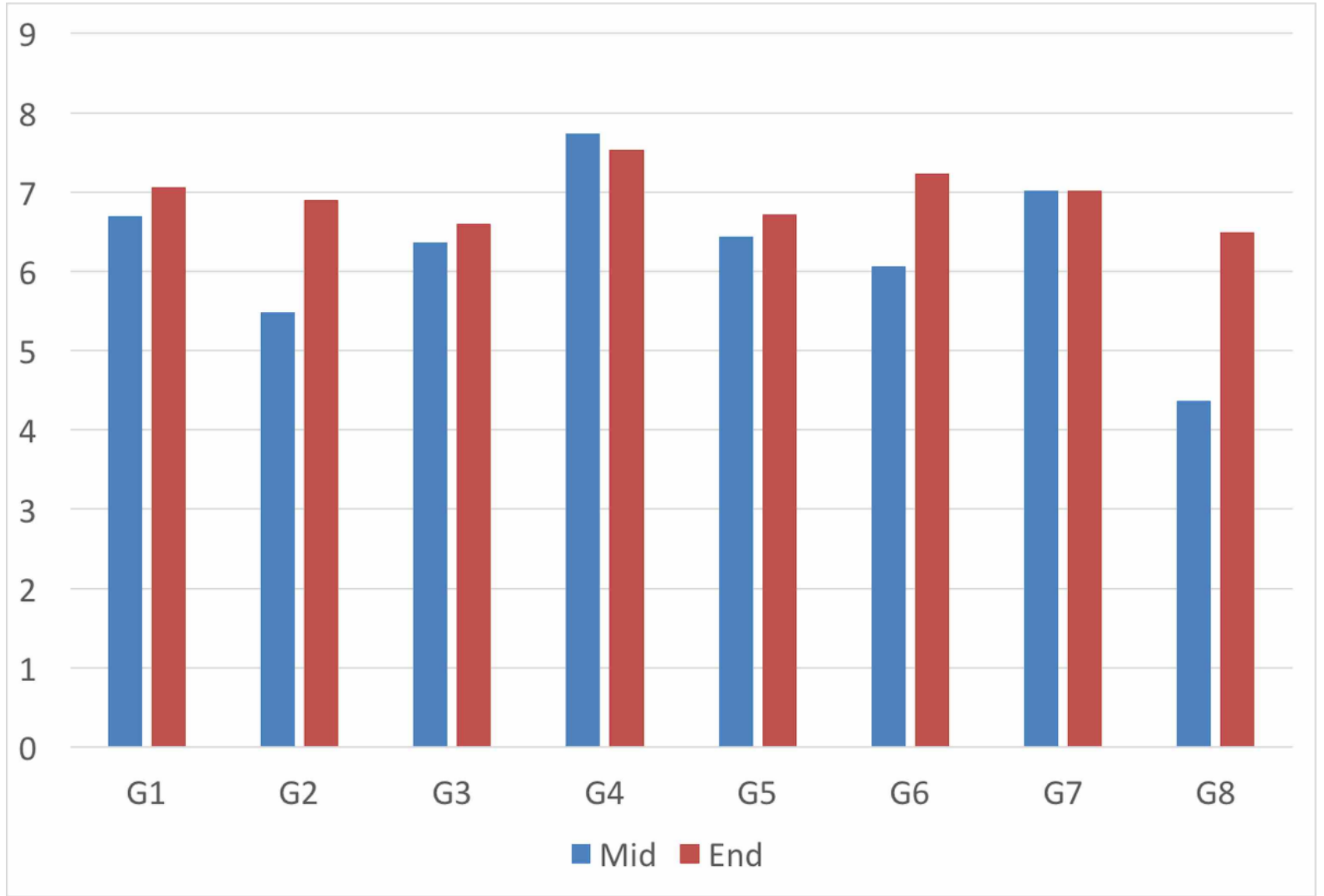

Fig. 6: Mean Opinion Score (MOS) of mid-sem. and end-sem., LA-SS PAC, Monsoon 2015. (X axis: Goals, $Y$ axis: Mean opinion score).

It can be observed from Fig. 6 that students appreciate the idea of the PAC. A comparative analysis between MOSs of mid and end-semester reveals that, while students had some inhibitions about PAC during the middle of the project, at the end they became appreciative about it. The mean opinion score suggests that students felt the significant improvement in content learning, critical thinking, and intrinsic motivation. During mid-semester review student felt that PAC may not have fairness in evaluation their viewpoint changed as the semester progressed and this is reflected in MOS of G8 after end-semester feedback. A significant increase in intrinsic motivation after week 5-6 can be attributed to the implementation and refinement phase during the PAC in the real-world context. Students also felt that the PAC (in its 2nd half of implementation phase) increased their content learning (mostly done during the first half of the project and during the coursework). Further, regular interactions and submissions also increased confidence in the fairness of evaluation in the proposed evaluation scheme of PAC.

MOS for goals G1 and G5 is high and has marginal increase due to the fact that PAC by definition was expected to offer these goals and a further increase in this MOS consolidates students understanding and beliefs in PAC for these goals. The opinion about competence in multiple areas suggests that student expectation was met. Thus, an overall observation making a positive case for PAC. 


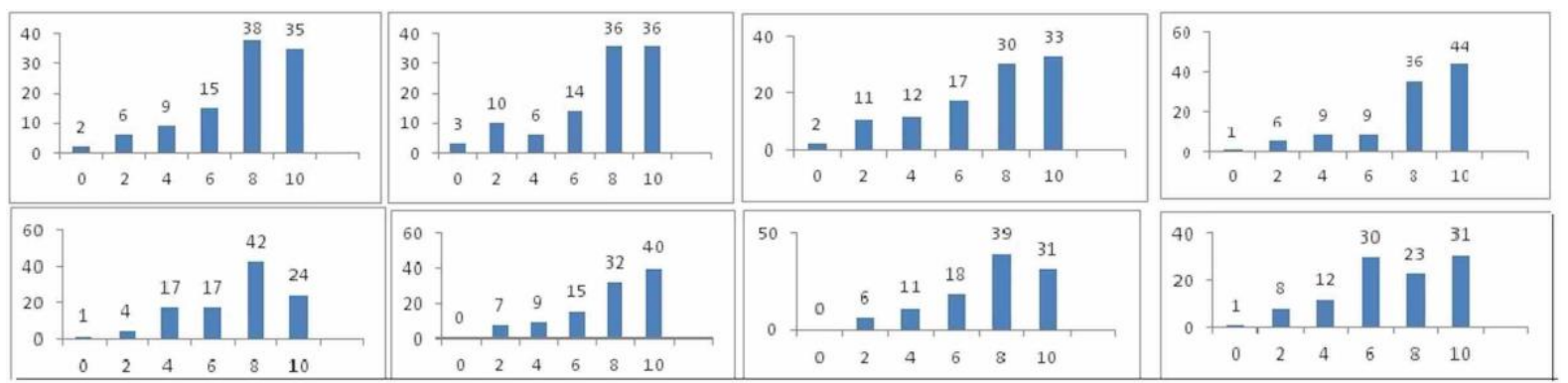

Fig. 7: Goal-wise opinion score distribution for LA - SS PAC evaluated at the end of semester. (X Axis - Opinion Score, Y Axis: Frequency - Number of Students).

Fig. 7 indicates goal-wise frequency distribution of the opinion score (OS) by 105 students of LA-SS PAC. It is evident that more than $80 \%$ of the students (OS $>6$ ) have shown the preference for PAC. Fig. 8 shows the goal wise standard deviation (SD) for LA - SS. It can be seen that compared to the mid-semester survey, standard deviation after end semester on average has reduced. This showcases consolidation of students' opinion. It can be observed that G3 SD rose the most. A possible reason can be large team size in which projection of team thinking may intermingle with an individual's thoughts.

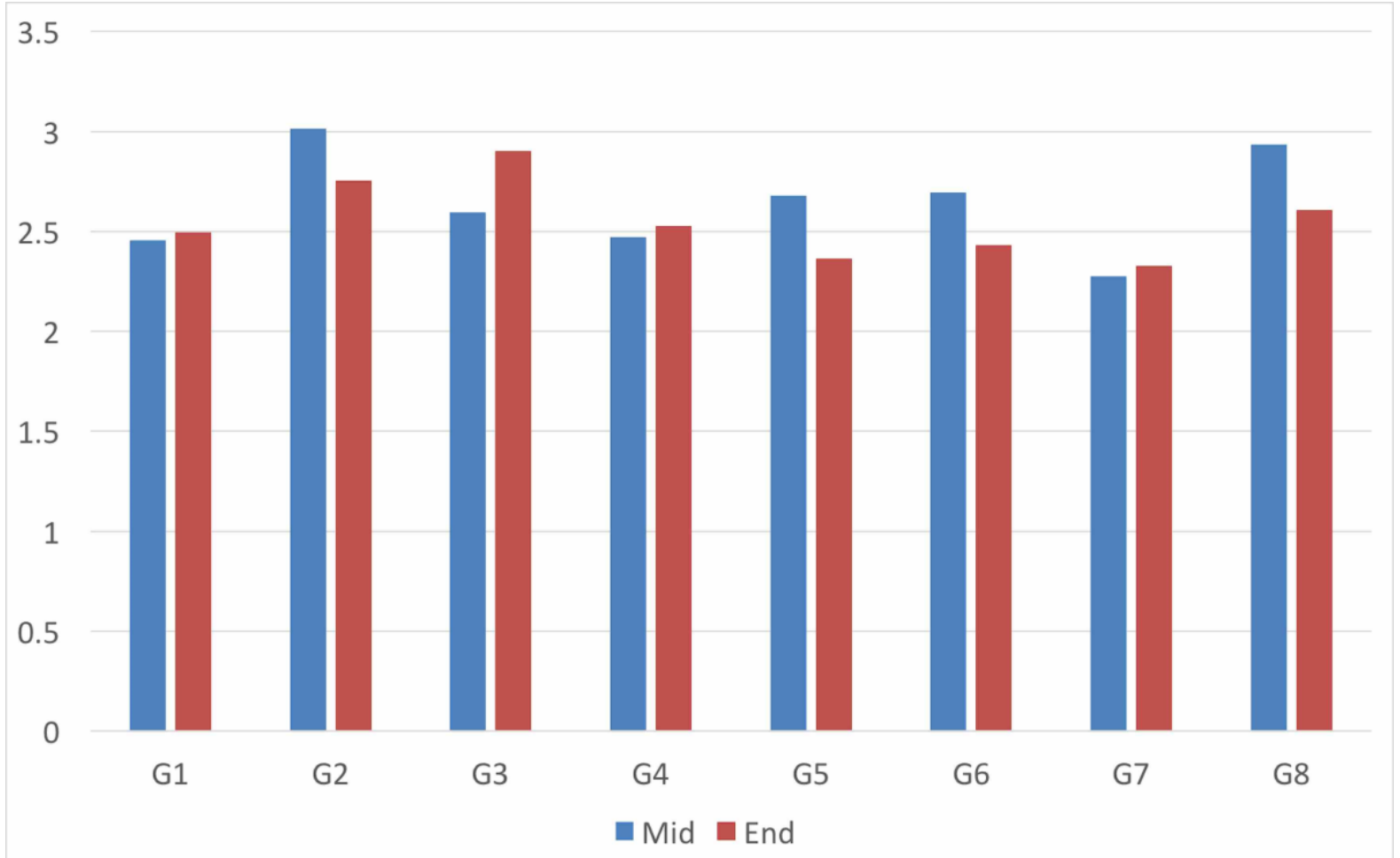

Fig. 8: Goal-wise standard deviation for LA - SS. (X Axis - Goals, Y Axis: Standard Deviation).

In order to support above observations through the quantitative measure of statistical significance, Cohen's $d$ [12] effect size between mid and end semester MOS was used. The results are shown in Table IX which suggests that content learning, critical thinking, intrinsic motivation, and fairness in project evaluation has value well above 0.2 (the small effect size). It shows improvement in these factors as PAC has progressed over the semester. Hands-on skills, Real world context, disciplinary integration and competence in multiple areas has Cohen's $d<0.2$ which shows that differences in their means between mid and end semester 
MOS are trivial. This means that students expected these goals to be fulfilled by PAC in the middle of the semester and at the end, they did meet.

TABLE IX: Goal wise Cohen's $d$ for LA - SS.

\begin{tabular}{|c|c|c|c|c|c|c|c|c|}
\hline Term & G1 & G2 & G3 & G4 & G5 & G6 & G7 & G8 \\
\hline Mid \& end & 0.14 & 0.49 & 0.34 & 0.08 & 0.11 & 0.45 & 0 & 0.77 \\
\hline
\end{tabular}

It would be also interesting to correlate the project score (PS) of PAC (e.g., LA-SS) and the total of the non-project scores $\left(\mathrm{NPS}_{\mathrm{t}}\right)$ of the subject (e.g., SS). The (NPS $)_{\mathrm{t}}$ indicates core domain competence and has scores of the mid-semester exam, end semester exam, assignments, quizzes. It would be worthy to study this correlation as PAC has common evaluation; jointly done by faculty (e.g., LA and SS) while non-project components will have an impact only from the course faculty (e.g., SS). Fig. 9 indicates linear regression of the PS against $\left(\mathrm{NPS}_{\mathrm{t}}\right.$ ) of the SS course. This finds the degree of overlap between the two types of evaluations. It can validate the hypothesis that better learners do well in both the components.
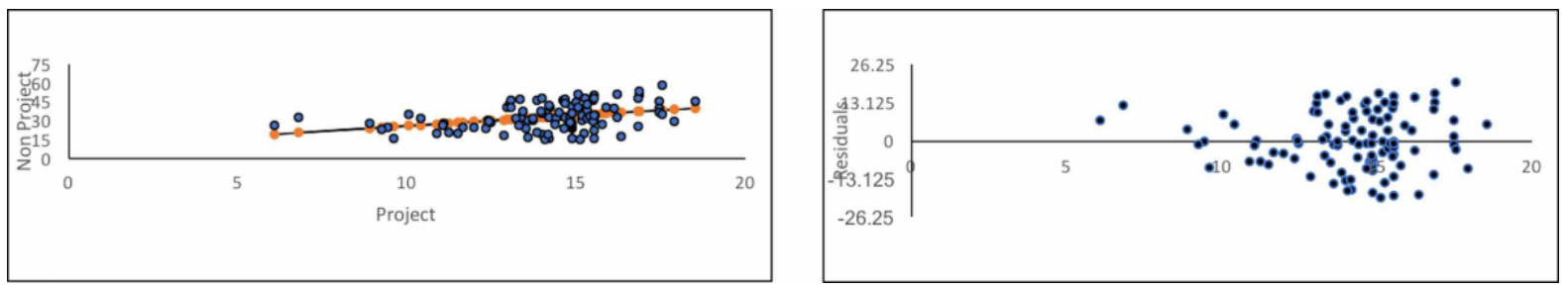

Fig. 9: Regression analysis and corresponding residuals for Signals and Systems (part of LA - SS PAC, Monsoon 2014 - 15). First Figure: X axis Project Score, Y axis Nonproject score).

The linear fit reported goodness of fit $\mathrm{R}^{2}=0.12$ at $5 \%$ level of significance. This validates the hypothesis about better learners. The analysis of residuals in Fig. 9 show their spread indicating the existence of regressive relationship throughout the range.

We also collected anonymous qualitative feedback through textual comments that supports PAC exercise, e.g., "...most of the times the intertwining nature of the courses were visible. I feel it is a good idea to have more projects across courses as they lessen the project burden..." It was very insightful to look into the team dynamics through peer feedback.

Figure 10 shows the comparison between the actual marks' distribution of PAC before and after incorporating peer review into the final evaluation. With peer review, the distribution spreads out. This is due to the fact that peer review captures internal team dynamics which usually remains opaque to faculty. 


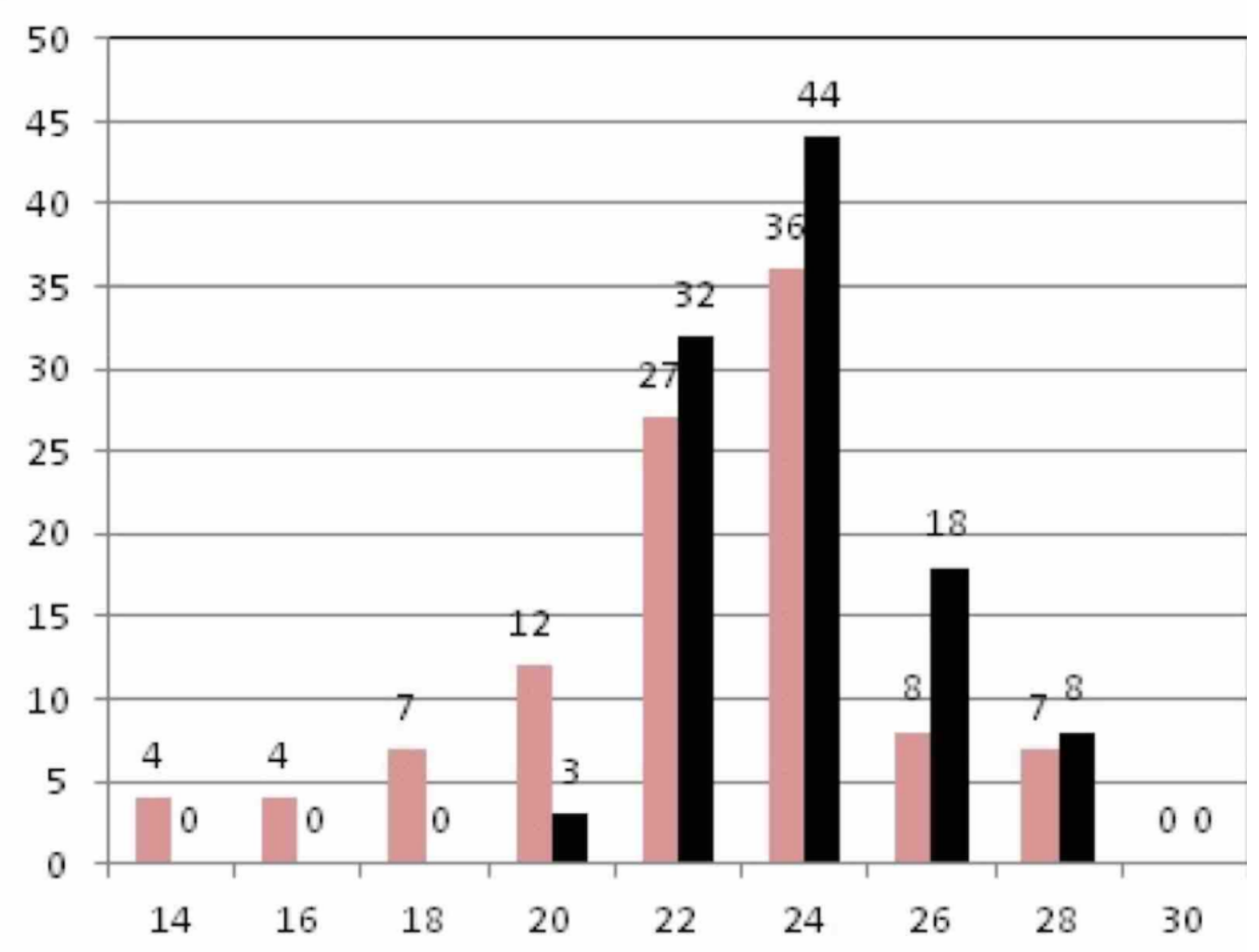

Fig. 10: Marks distribution - with and without peer feedback for LA-SS PAC Monsoon 2015. (X axis: Marks Bin, $Y$ axis: Frequency).

D. Educational Assessment: $A O B D$ - $M L$

Anonymous opinion scores in AOBD - ML PAC were also collected. The MOS after the end of the AOBD - ML PAC for three consecutive offering is shown in Fig. 11. It is important to note that AOBD - ML PAC had BTech and MTech students. In this study mean opinion score collected before the beginning of the PAC reports student's expectations and after its end represents the outcome. It is very interesting to observe that here too students have opted for PAC as a preferred modality. The scores for the second (winter 2015 - 16) and third (winter 2016 - 17) is higher than first (winter 2014 - 15) PAC run. The low MOS for 2014 - 15 could be attributed to the first run of any PAC at the School. The faculty, TAs and students were going through their first experience of PAC. The improvement in processes and problem statement (face recognition vs. face detection) improved the MOS significantly. It can be seen from MOS that students felt the significant improvement in all project aspects during its subsequent run in winter 2015 - 16. 


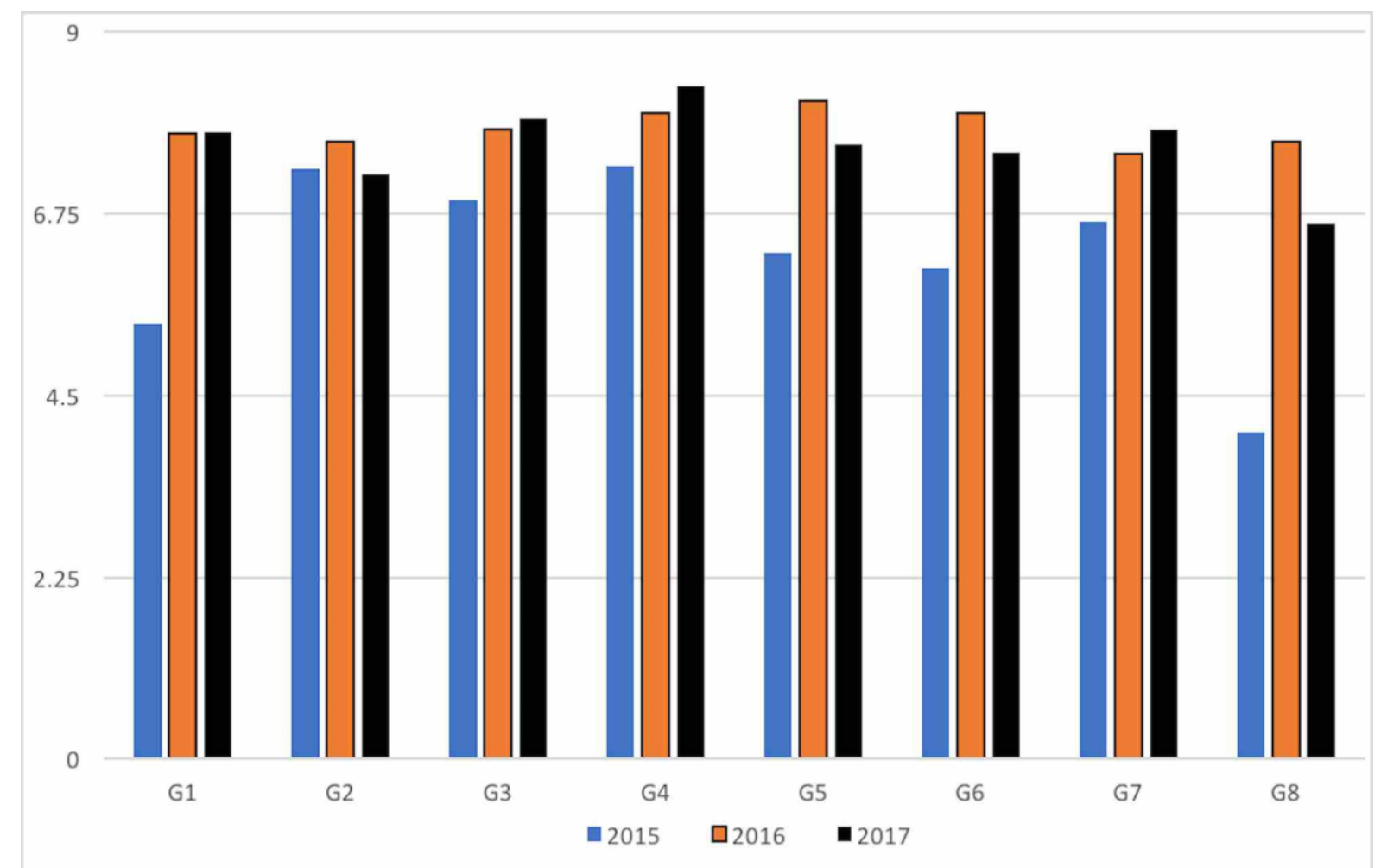

Fig. 11: Mean Opinion Score of satisfaction survey after project end for AOBD - ML. (X axis: Goals, Y axis: Mean opinion score).

The standard deviation in each of these MOS for three years are captured in Fig. 12. It is an interesting plot to study variability in students' thought process. During the first run, SD is high for all the MOS. It has an average value (across all goal's SD) of 2.47 on a scale of 10 . Due to improvisation in the problem statement, treatment by faculty, and training of the TA's, technical and learning skills of the students improved. Most students liked the idea of PAC and therefore there is a consolidation of liking towards PAC in 2015-16. This reflects in lower average SD with a value of 1.37. The problem statement changes and increase in population brought a slight increase in average SD to 1.92 in 2016 - 17. But this is still smaller than average SD (2.47) in 2014 - 15. 


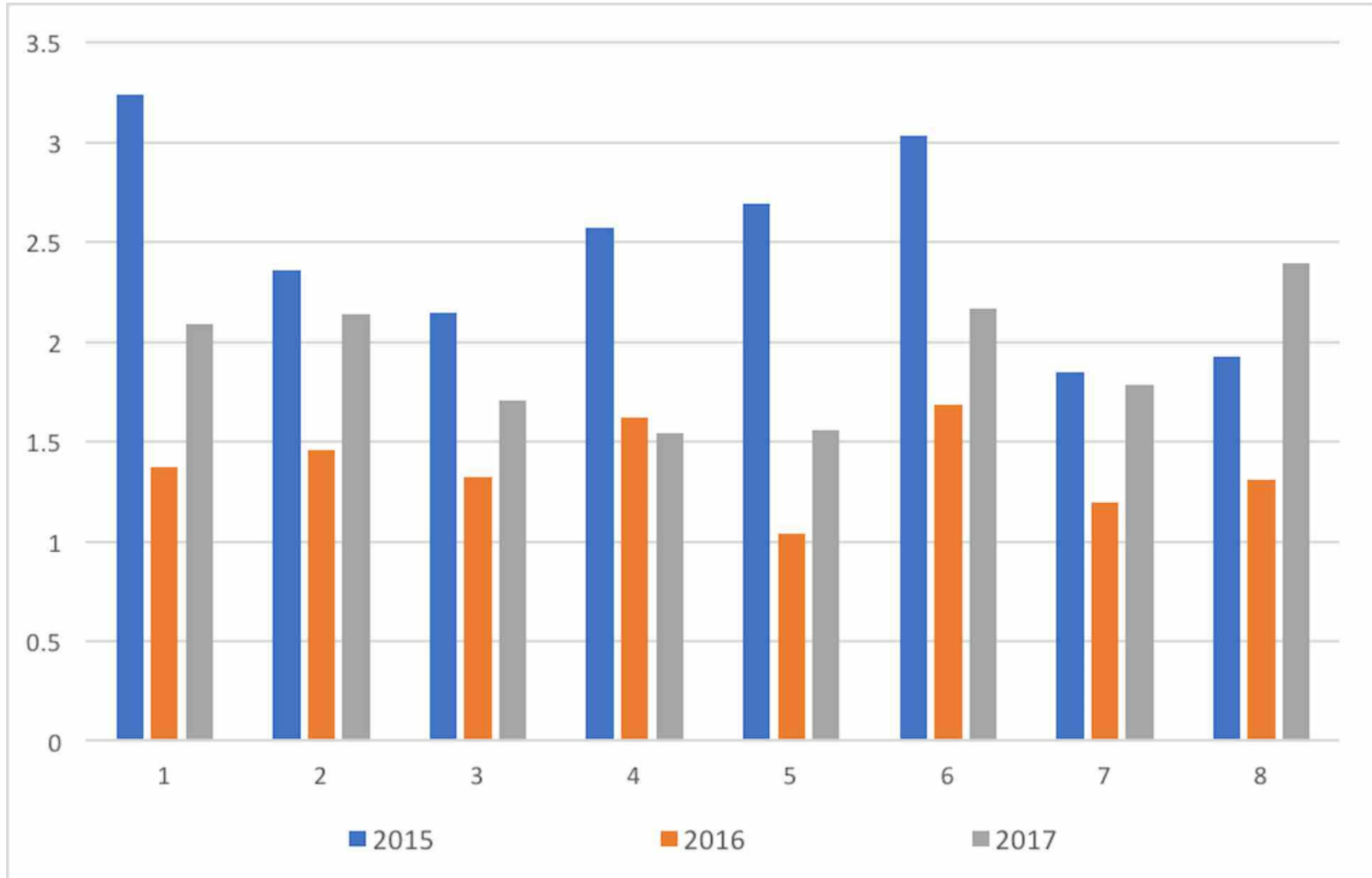

Fig. 12: Standard deviation after project end for AOBD - ML. (X axis: Goals, Y axis: Standard Deviation).

The results are quantified through Cohen's $d$ effect size in the Table X. The students felt the significant improvement in hands-on skills, critical thinking, real-world context, disciplinary integration, intrinsic motivation, competence in multiple areas, and fairness of project evaluation. The Cohen's $d$ effect size is significantly larger than 0.2 for all these MOS. The MOS for G2 (content learning) improves from 7.3 (2014 - 2015) to 7.65 (2015 - 2016) resulting in Cohen's $d$ of 0.17. This shows that the students continued to anticipate better content learning through PAC. Comparing runs of 2014 - 15 and 2016 - 17 PACs also show significant improvement for the goals. Also, one can observe that Cohen's $d$ effect size is smaller in between 2014 - 2015 \& 2016 - 2017 than 2014 - 2015 and 2015 - 2016 offerings. The reason for this smaller change is due to; 1. Change in problem definition in 2016 - 17 (Image generation) compared to 2014 - 15 (Face detection); 2. There are more students (53) in 2016 17 than 32 in $2014-15$.

TABLE X: Goal wise Cohen's $\boldsymbol{d}$ for AOBD - ML.

\begin{tabular}{|c|c|c|c|c|c|c|c|c|}
\hline Year & G1 & G2 & G3 & G4 & G5 & G6 & G7 & G8 \\
\hline $14-15 \& 15-16$ & 0.96 & 0.17 & 0.49 & 0.3 & 0.92 & 0.78 & 0.54 & 2.2 \\
\hline $14-15 \& 16-17$ & 0.52 & 0.05 & 0.25 & 0.44 & 0.57 & 0.37 & 0.6 & 0.88 \\
\hline
\end{tabular}




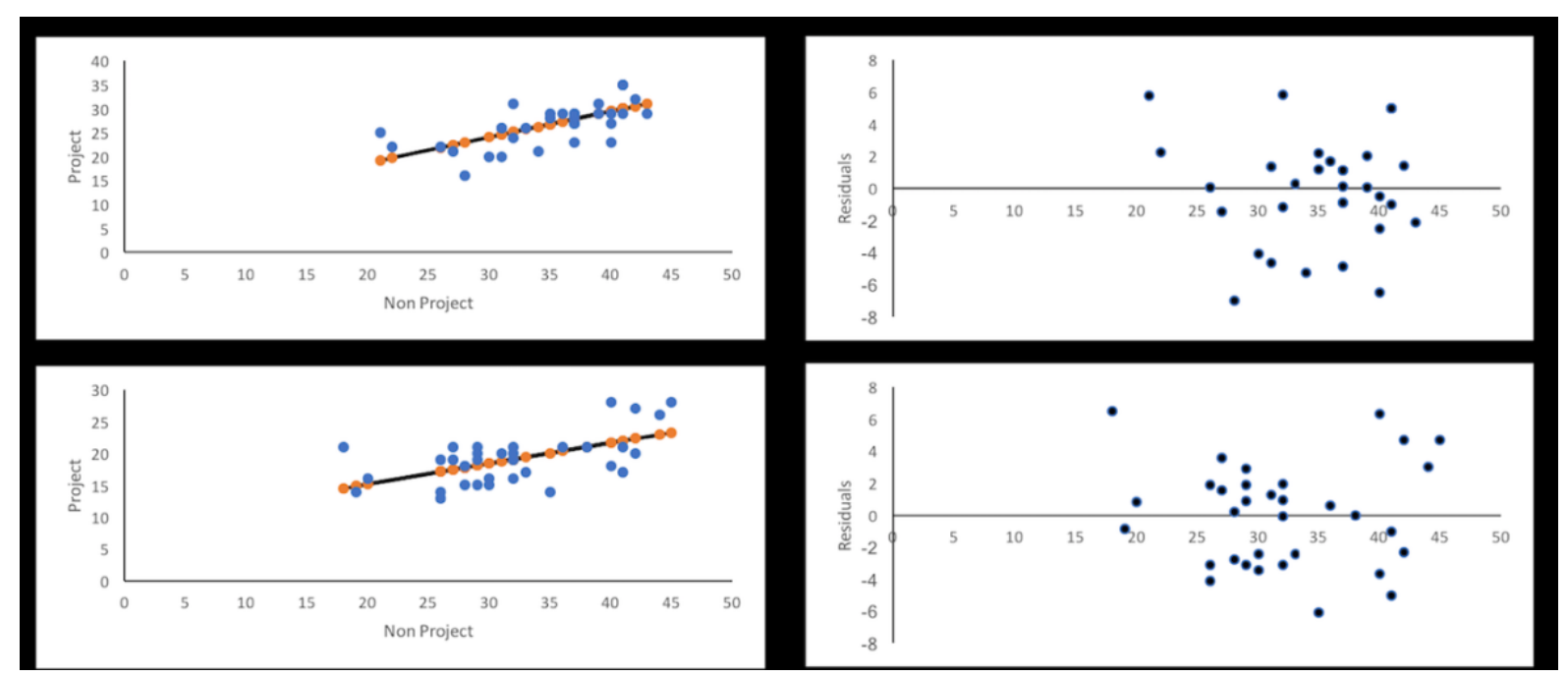

Fig. 13: Regression analysis and corresponding residuals for AOBD (part of AOBD - ML PAC). First Row: Line Fit $\left(R^{2}=0.45\right)$ and residuals for Winter 2015 - 16. Second row: Line Fit $\left(R^{2}=0.33\right)$, residuals for Winter 2016 - 17. Axes in regression X: NPS, Y: PS.
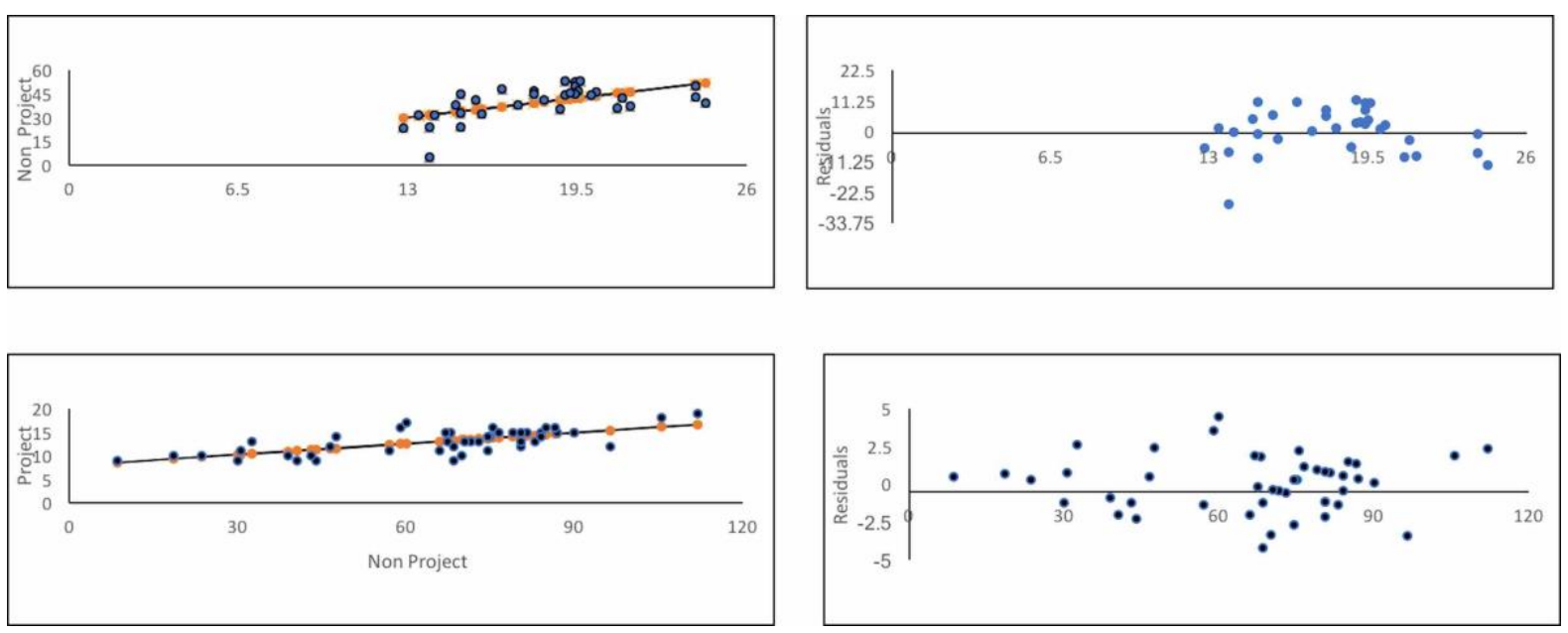

Fig. 14: Regression analysis and corresponding residuals for Machine Learning (Part of AOBD - ML PAC). Top row: Line fit $\left(R^{2}=0.32\right)$ and residuals, Winter 2015 - 16. Second Row: Line fit $\left(R^{2}=0.48\right)$ and residuals, Winter 2016 - 17. Axes in regression X: NPSt, Y: PS.

The statistical analysis involving regression of PS against $\left(\mathrm{NPS}_{\mathrm{t}}\right)$ of AOBD and ML is shown in Fig.13 and Fig.14 respectively. The goodness of fit $\mathrm{R}^{2}$ was computed at $5 \%$ level of significance. The statistical relationship for three years reported $\mathrm{R}^{2}$ values of 0.45 and 0.33 respectively for the AOBD course. At the same time $\mathrm{R}^{2}$ values are 0.32 and 0.48 for the ML course during 2015 - 16 and 2016 - 17. The above observations for both the courses validate the NULL $\left(\mathrm{H}_{0}\right)$ hypothesis i.e., better learners do well in the project and the non-project components of the courses involved in the PAC. The analysis of residuals in Fig.13 and Fig.14 shows their spread in the score range. This indicates the existence of regressive relationships throughout the range.

Some of the comments from the students on this exercise is worth noting, e.g., "Project across course helps in understanding how to apply the theoretical concepts from both the courses in 
the real world...". Many echoed that learning both AOBD and ML was fun because they can easily relate whatever learned in the class through project.

The above analysis and comments show that PAC is able to assess technical and life skills. The life skills are complementary to core domain skills. The PAC assess life skills which are independent of core technical skills. This fact is established due to low $\mathrm{R}^{2}$ values between PS and NPS $\mathrm{t}_{\mathrm{t}}$ for all the courses involved in PAC.

\section{CONCLUSION AND FUTURE PLANS}

The work presented an active learning tool - Project across courses - to develop technical and life skills of engineering students. It shows how to design and position multidisciplinary projects in the constrained environment e.g., LA-SS PAC.

The PAC had slightly loose project definition which made students think critically and it also left room for admitting multiple solutions. The timeline suggested several sub-tasks which can be solved only by a team. The statistical analysis through Cohen's $d$ and MOS suggested that students showed affinity to PAC. The regression analysis also showed that good learners do well in both project and non-project components. More importantly, students learn complementary skills through these two components independently. The observations derived from the goals mapped to the learning objectives consolidates our belief that PAC is a relevant AL pedagogy for constrained environment.

Even though initial results are encouraging for a large class PAC, it is far from being perfect. Forming balanced student teams that are not too large is difficult. These imbalances were echoed in several student feedbacks. Many comments also highlighted tussle between academically strong and mediocre student(s) in a large team. Working on an open-ended project definition for third-semester students is also challenging as some students found the change from conventional pedagogy was difficult. Most importantly faculty has to dedicate a significant amount of time outside the class hours to the students. Since only two faculties share the group of 105 students, it's extremely challenging to dedicate enough time for all the groups.

Another long-term study on heterogeneous (BTech and MTech) group also suggested affinity towards PAC. The MOS score of the student satisfaction survey showed significant consolidation of liking towards PAC over the years. The statistical analysis also supported MOS observations. Most interestingly, regression and residuals showed that combination of PAC and conventional evaluation approach are complementary. This shows the utility of PAC as a good tool for AL in the constrained environment.

There are several challenges to heterogeneous PAC. Apart from known challenges of large faculty time requirements, and trained TAs, our experiments had another unique situation. PAC offering has to handle different (number of) student registration in AOBD and ML courses each year. The MTech numbers are same for these courses but the number of BTech students vary as AOBD and ML are elective for them. Following Table XI reveals the actual registrations numbers. During 2015 - 16 AOBD and ML pair was offered as a single bouquet i.e., a student had to opt for both of these electives together. This, we found, to be very restrictive, therefore, the condition was relaxed in 2016 - 17 offering. This resulted in very different numbers. Now the faculty has to deal with two different projects - one in AOBD ML PAC and other as PIC in the same offering of a course to different students. This further constrains the faculty time. 
Evaluation of heterogeneous group is also very challenging. More so, sometimes it is difficult to assume similar understanding on prerequisite from the sub groups in a class. E.g., difference in treatment received by BTech and MTech students is very difficult to bridge. It has been observed that due to better prerequisite coverage, on an average, BTechs' learns and performs better than MTechs. This challenges the evaluation and faculty may have to set evaluation benchmarks differently.

TABLE XI: BTech Students enrolled in AOBD \& ML.

\begin{tabular}{|c|c|c|c|}
\hline Course & $2014-15$ & $2015-16$ & $2016-17$ \\
\hline AOBD & 18 & 25 & 47 \\
\hline ML & 16 & 25 & 75 \\
\hline
\end{tabular}

The following can be future directions (as a variant of current offerings of PAC): 1. refinement of evaluation mechanism, 2. strengthening of peer review system, 3. enrollment of larger set of TAs for designing dynamics at instruction/coaching level, 4. involving industrial partner for project definition, 5. motivating other faculty members to be a part of this experimentation so that more numbers of courses participate in PAC offering.

There has been an introduction of active learning in freshman year of engineering at the University. These courses are taught by the relatively small group of faculty members. Many faculties find it difficult and uncomfortable due to the efforts and time involved in AL course offerings. This has also been reported in the schools across US [24] and it needs serious thought process at University to encourage more faculty participation.

Encouraged by results of large PAC class offering, three courses (LA, SS and Computer Organization) were combined in BTech ICT semester III during Monsoon 2017 - 18 semester. The idea was to complete the chain using both hardware and software. The preliminary results are encouraging but it needs long-term investigations. Therefore, we will work with PAC across three courses in future offerings.

\section{ACKNOWLEDGMENTS}

Authors would like to thank colleagues Pratik Trivedi, Nishit Pandya, Chetan Parikh, Sanjay Chaudhary, and Ashok Ranade for helping us shake the AL tree at the University. The authors also acknowledge support of University management in carrying out this work. The authors would also like to acknowledge stimulating discussions on AL with colleagues from Olin College of Engineering, Needham MA.

\section{REFERENCES}

[1] ACPC, The admission committee for professional courses, Gujarat, India. (n.d.). Retrieved April 12, 2018, from http://www.jacpcldce.ac.in/be.asp.

[2] AICTE, AICTE engineering and technology intake for UG and PG. (2018, January 11). Retrieved April 12, 2018, from https://www.facilities.aicteindia.org/dashboard/pages/dashboardaicte.php

[3] AICTE, AICTE model curriculum 2018. (2018). Retrieved April 12, 2018, from https://www.aicte-india.org/sites/default/files/Vol. I UG.pdf. 
[4] Berrett, D. (2012). Lectures still dominate science and math teaching, sometimes hampering student success. The Chronicle of Higher Education.

[5] Bloom, B. S. (1971). Taxonomy of Educational Objectives: The Classification of Educational Goals: By a Committee of College and University Examiners. David McKay.

[6] Brady, C., Orton, K., Weintrop, D., Anton, G., Rodriguez, S., \& Wilensky, U. (2017). All roads lead to computing: Making, participatory simulations, and social computing as pathways to computer science. IEEE Transactions on Education, 60(1), 59-66.

[7] Cabre, T. P., Cairol, M. T., Calafell, D. F., Ribes, M. T., \& Roca, J. P. (2013). Project-based learning example: controlling an educational robotic arm with computer vision. IEEE Revista Iberoamericana de Tecnologias del Aprendizaje, 8(3), 135-142.

[8] Calvo, I., Cabanes, I., Quesada, J., \& Barambones, O. (2018). A Multidisciplinary PBL Approach for Teaching Industrial Informatics and Robotics in Engineering. IEEE Transactions on Education, 61(1), 21-28.

[9] Carrió, M., Agell, L., Baños, J. E., Moyano, E., Larramona, P., \& Pérez, J. (2016). Benefits of using a hybrid problem-based learning curriculum to improve long-term learning acquisition in undergraduate biology education. FEMS microbiology letters, 363(15).

[10] Chang, M. (2000). Engineers in the 21st Century. IEEE Journal of Selected Topics in Quantum Electronics, 6(6), 976-977.

[11] Chen, C. Y., Hong, Y. C., \& Chen, P. C. (2014). Effects of the meetings-flow approach on quality teamwork in the training of software capstone projects. IEEE Transactions on Education, 57(3), 201-208.

[12] Cohen, J. (1992). A power primer. Psychological bulletin, 112(1), 155.

[13] Corral Abad, E., Gómez García, M. J., Ruiz Blázquez, R., Castejon, C., \& García-Prada, J. C. (2018). Effects of an android app on mechanical engineering students. Computer Applications in Engineering Education, 26(4), 1050-1057.

[14] DeSeCo, O.E.C.D. (2005). The definition and selection of key competencies. Executive summary :http://www.deseco.admin. ch/bfs/deseco/en/index/02. html.

[15] Dewey, J. (1980). The school and society (Vol. 151). Carbondale: SIU Press. Google Scholar.

[16] Dym, C. L., Agogino, A. M., Eris, O., Frey, D. D., \& Leifer, L. J. (2005). Engineering design thinking, teaching, and learning. Journal of Engineering Education, 94(1), 103-120.

[17] Farrell, J. J., Moog, R. S., \& Spencer, J. N. (1999). A guided-inquiry general chemistry course. Journal of chemical education, 76(4), 570.

[18] Freeman, S., Eddy, S. L., McDonough, M., Smith, M. K., Okoroafor, N., Jordt, H., \& Wenderoth, M. P. (2014). Active learning increases student performance in science, 
engineering, and mathematics. Proceedings of the National Academy of Sciences, 111(23), $8410-8415$

[19] Garduño-Aparicio, M., Rodríguez-Reséndiz, J., Macias-Bobadilla, G., \& Thenozhi, S. (2018). A Multidisciplinary Industrial Robot Approach for Teaching Mechatronics-Related Courses. IEEE Transactions on Education, 61(1), 55-62.

[20] Gary, K. (2015). Project-based learning. Computer, 48(9), 98-100.

[21] Geronimo, D., Serrat, J., Lopez, A. M., \& Baldrich, R. (2013). Traffic sign recognition for computer vision project-based learning. IEEE Transactions on Education, 56(3), 364-371.

[22] Goldberg, D. E., \& Somerville, M. (2014). A whole new engineer. The coming revolution in Engineering Education. Douglas MI: Threejoy.

[23] Hanney, R., \& Savin-Baden, M. (2013). The problem of projects: understanding the theoretical underpinnings of project-led PBL. London Review of Education, 11(1), 7-19.

[24] Haungs, M., Clements, J., \& Janzen, D. S. (2008). Improving Engineering Education Through Creativity, Collboration, and Context in a First Year Course. In American Society for Engineering Education Annual Conference: Pittsburgh, PA.

[25] Henri, M., Johnson, M. D., \& Nepal, B. (2017). A Review of Competency-Based Learning: Tools, Assessments, and Recommendations. Journal of Engineering Education, 106(4), 607-638.

[26] Hosseinzadeh, N., \& Hesamzadeh, M. R. (2012). Application of project-based learning (PBL) to the teaching of electrical power systems engineering. IEEE Transactions on Education, 55(4), 495-501.

[27] Huet, I. (2017). based education as a model to change the teaching and learning environment in STEM disciplines. European Journal of Engineering Education, 1-16.

[28] J. Duffany, J. L. (2017). Application of Active Learning Techniques to the Teaching of Introductory Programming. IEEE Revista Iberoamericana de Tecnologias del Aprendizaje, 12(1), 62-69.

[29] Kerns, S. E., Miller, R. K., \& Kerns, D. V. (2005). Designing from a blank slate: The development of the initial Olin College curriculum. Educating the engineer of 2020: Adapting engineering education to the new century, 98-114.

[30] Kirn, A., \& Benson, L. (2015). Engineering students' perceptions of the future: Exploratory instrument development. In 122nd ASEE Annual Conference \& Exposition.

[31] Lamar, D. G., Miaja, P. F., Arias, M., Rodríguez, A., Rodríguez, M., Vázquez, A., \& Sebastián, J. (2012). Experiences in the application of project-based learning in a switchingmode power supplies course. IEEE Transactions on education, 55(1), 69-77. 
[32] Lattuca, L. R., Knight, D. B., Ro, H. K., \& Novoselich, B. J. (2017). Supporting the Development of Engineers' Interdisciplinary Competence. Journal of Engineering Education, 106(1), 71-97.

[33] Mannan, S. M. (2018, March 04). New AICTE rule on staff ratio puts engineering college faculty in line of fire in Tamilnadu. Retrieved April 12, 2018, from http://www.newindianexpress.com/states/tamil-nadu/2018/mar/04/new-aicte-rule-on-staffratio-puts-engineering-college-faculty-in-line-of-fire-in-tamil-nadu-1781730.html.

[34] Mantri, A., Dutt, S., Gupta, J. P., \& Chitkara, M. (2008). Design and evaluation of a PBLbased course in analog electronics. IEEE Transactions on Education, 51(4), 432-438.

[35] Martinez-Rodrigo, F., Herrero-De Lucas, L. C., de Pablo, S., \& Rey-Boue, A. B. (2017). Using PBL to Improve Educational Outcomes and Student Satisfaction in the Teaching of DC/DC and DC/AC Converters. IEEE Transactions on Education, 60(3), 229-237.

[36] McGourty, J. (2000). Using multisource feedback in the classroom: A computer-based approach. IEEE transactions on education, 43(2), 120-124.

[37] Murray, C. (2011). Engineering in the Twenty-First century. Harvard Magazine.

[38] Oakley, B., Felder, R. M., Brent, R., \& Elhajj, I. (2004). Turning student groups into effective teams. Journal of student centered learning, 2(1), 9-34.

[39] Passow, H. J., \& Passow, C. H. (2017). What Competencies Should Undergraduate Engineering Programs Emphasize? A Systematic Review. Journal of Engineering Education, 106(3), 475-526.

[40] Petkovic, D. (2016). Using Learning Analytics to Assess Capstone Project Teams. Computer, 49(1), 80-83.

[41] Pimmel, R. L. (2003). A practical approach for converting group assignments into team projects. IEEE Transactions on Education, 46(2), 273-282.

[42] Prince, M. (2004). Does active learning work? A review of the research. Journal of engineering education, 93(3), 223-231.

[43] Prince, M. J., \& Felder, R. M. (2006). Inductive teaching and learning methods: Definitions, comparisons, and research bases. Journal of engineering education, 95(2), 123138.

[44] Sanchez, G. F., Guzman, M. V., Gomez, I. S., Riveros, K. W., Muller, M. A. P., \& Ortega, J. S. (2015). Project-based learning versus cooperative learning courses in engineering students. IEEE Latin America Transactions, 13(9), 3113-3119.

[45] Seman, L. O., Hausmann, R., \& Bezerra, E. A. (2017). Agent-Based Simulation of Learning Dissemination in a Project-Based Learning Context Considering the Human Aspects. IEEE Transactions on Education. 
[46] Shuman, L. J., Besterfield-Sacre, M., \& McGourty, J. (2005). The ABET "professional skills"-Can they be taught? Can they be assessed?. Journal of engineering education, 94(1), 41-55.

[47] Strawn, G. (2017). IT and 21st Century Employment. IT Professional, 19(6), 71-73.

[48] Tang, J., Liu, S., Pei, S., Zuckerman, S., Liu, C., \& Gaudiot, J. L. (2018). Teaching Autonomous Driving Using a Modular and Integrated Approach. arXiv preprint arXiv:1802.09355.

[49] Verbič, G., Keerthisinghe, C., \& Chapman, A. C. (2017). A Project-Based Cooperative Approach to Teaching Sustainable Energy Systems. IEEE Transactions on Education, 60(3), 221-228.

[50] Warin, B., Talbi, O., Kolski, C., \& Hoogstoel, F. (2016). Multi-role project (MRP): A new project-based learning method for STEM. IEEE Transactions on Education, 59(2), 137-146. 